\title{
Expediente gobernativo instruído a Hermenegildo Calvelo, mestre da escola completa de nenos de Cuntis (1894-1896)
}

\author{
Narciso DE GABRIEL \\ Universidade da Coruña
}

Reproducimos seis dos documentos que integran un dos dous expedientes gobernativos instruídos ao mestre Hermenegildo Calvelo, comentados nun artigo que aparece nas páxinas anteriores. Esta documentación está depositada no Arquivo Histórico Universitario de Santiago, Ensino primario, caixa 171.

\section{Documento 1. Informe do xuíz municipal ao alcalde de Cuntis}

Evacuando el informe que V. interesa en su oficio fecha 4 de los corrientes, respecto a la conducta moral y profesional del Maestro de niños de esta Villa, D. Hermenegildo Calvelo, debo manifestar:

Primero. Que es público y notorio en este pueblo que el tal funcionario, desde que se encargó de la Escuela, vino pasando la mayor parte del tiempo en la taberna de José de la Fuente, saliendo de ella bastante tarde y muchas veces contento, cuyo género de vida continúa haciendo de algunos días a esta parte en el café de D. Antonio Rivas Sueiro.

Segundo. Que vive separado de su distinguida y virtuosa esposa, a la cual, según de público se dice, tiene completamente abandonada.

Tercero. Cuando se encargó de la escuela le acompañó su buena madre, la cual, a pesar de su bondadoso carácter, no pudo soportar el comportamiento que con ella tiene el D. Hermenegildo; así que aquella anciana y virtuosa viuda tuvo que abandonar este país y retirarse a vivir, según se dice, en compañía de familia extraña, en el lugar de Rojos, a imediaciones [sic] de la ciudad de Santiago; cuya extrema determinación adoptó después de persuadirse de que su hijo, no obstante ser único, no atendía a los sanos consejos que le daban tanto ella como varias personas, entre las cuales merecen citarse D. Manuel Ballesteros Gil, cura que ha sido de esta parroquia, y en la actualidad de la de S. Miguel de la ciudad de Santiago, D. Nicolás García Garrido, capellán de esta parroquia, D. Manuel Barreiro García, Médico de Consigna del Lazareto de Oza, los que a pesar de sus reiteradas gestiones no han podido conseguir que el Maestro Calvelo despidiese de su casa a una joven doméstica, causa de los disgustos que sufría y lamentaba su pobre madre.

Cuarto. Tanto deja que desear la conducta que viene observando dicho Maestro que ha llegado al extremo de perder todo su ascendiente moral, hasta con los niños que concurren a la Escuela, que estos se han permitido dedicarle una cencerrada. 
Quinto. Es tan poco el celo que viene demostrando por la enseñanza que la mayor parte de los días en vez de dedicar a ella las horas reglamentarias, las pasa en sus habitaciones particulares; y cuando no, se entretiene en pasear con sus íntimos amigos el Fiscal Municipal, D. Vicente Carballo, D. Miguel da Torre, Secretario del Ayuntamiento, D. Pedro Blanco, Secretario del juzgado municipal, D. Laureano Alonso, Fiscal suplente, etc., dando lugar a que los padres, entre ellos D. Eugenio Aboy García, D. José Fariña Barreiro, D. Joaquín Gómez Losada, D. José Lajo Fraga, D. Manuel Piñeiro Couso, D. Enrique Campos Aboy, D. Antonio Rivas Sueiro, D. Modesto Garrido, D. Andrés Ferradáns Maceira, Josefa González, viuda de Gómez, y otros muchos que sería prolijo enumerar, se vieran en la necesidad de mandar sus hijos respectivos a escuelas particulares.

Sesto [sic]. El aludido abandono parece que viene consintiéndose desgraciadamente por la mayoría de las personas que, por razón de su cargo oficial, eran las llamadas a ponerlo en conocimiento de las autoridades superiores, a fin de cortarlo; y si aún no lo han hecho, será debido tal vez a la amistad que aquellas dispensan al referido Maestro.

Si se intentara desvirtuar lo espuesto [sic] por lo que declaren unos pocos padres de familia, o por otros medios, será devido [sic] a influencias perniciosas que se pongan en juego por algunos amigos del referido Maestro; los cuales, aunque persuadidos de que no merece estar al frente de la escuela, lo apoyan no obstante por razones de conveniencia política.

Por último, también contribuirían al esclarecimiento de los indicados hechos el informe que pudiera emitir el Capellán del Convento de Monjas de Pereira, D. José Hermo, D. Pedro Casto Rivas, presbítero, y el Sr. Rector párroco de esta Villa.

Es todo lo que en conciencia puedo y debo informar a V., interesándole se sirva acusarme recibo.

Dios guarde a V. m. a.

Cuntis, Septiembre 8 de 1894

Joaquín Barreiro García

\section{Documento 2. Informe do inspector provincial da Coruña ao reitor da Universidade de Santiago}

En cumplimiento de la orden que en 8 del corriente ha recibido de V. E. me he trasladado a Cuntis, Pontevedra, y procurado averiguar el concepto público que merece D. Hermenegildo Calvelo, Maestro de la escuela municipal de niños de aquella Villa, así por su conducta moral, como por su comportamiento profesional. 
No es tarea fácil en un pueblo tan dividido y maleado por el inmoderado afán de preponderancia en la administración de los intereses procomunales, llegar al conocimiento de la verdad en asuntos movidos al calor de los odios y resentimientos que estas luchas ocasionan, más que al del amor al bien público.

Creo, sin embargo, haber formado un juicio, a mi parecer, exacto respecto al valor real que tienen las acusaciones lanzadas contra el Maestro y del mérito de éste considerado bajo los dos puntos de vista, moral y profesional.

D. Hermenegildo Calvelo no es solamente ilustrado, capaz y apto para el ejercicio del Magisterio, cumple también sus deberes morales y no desatiende los profesionales.

Para llegar a esta conclusión, claro es que he huido por igual de informarme de las personas que pudieran estar interesadas de modo ostensible en pro o en contra del acusado y que he procurado oír a cuantos, por su alejamiento de las apasionadas luchas locales, me ofrecían garantías de imparcialidad.

He visitado en primer lugar al Sr. D. Isolino Suárez, ilustradísimo y venturoso párroco de Cuntis, y que se distingue por su rectitud y justificación.

Este respetable Sacerdote me ha dicho por primera contestación a mis indicaciones que nada tenía que rectificar de lo que había informado oficialmente en 6 de Septiembre último.

-Pero ese oficio, le contesté, es una contradicción de la carta que V. escribió en 16 de Junio anterior contestando a otra del Sr. Rector, y por eso ruego a V. en nombre del mismo Sr. Rector que tenga la bondad de decirme cuál de los dos informes debe ser tomado en consideración, y de darme la clave de dicha contradicción, que a nosotros nos confunde.

-Es muy sencilla la explicación, me replicó, y con mucho gusto la daré a V.

Al escribir, continuó, la contestación a la carta del Sr. Rector, me hice eco de las noticias que me habían dado personas que yo creía desinteresadas y fidedignas. Pero luego hube de rectificar mis juicios por haberme convencido no sólo de la falta de sinceridad de los informantes, sino de [que] éstos no tenían más que odio e inquina contra el Maestro. Yo nunca he visto a éste en estado de embriaguez y a nadie oí que le imputase este vicio más que a sus enemigos; y a éstos y no a otro alguno debo la noticia de que sea jugador y de que se retire del café a altas horas de la noche. Y solo a un extraño a tales enemistades, a mi Sacristán, he oído quejarse de que no era demasiado puntual para presentarse en la Escuela. Debo consignar en cambio, que, alguna vez que he visitado a ésta, observé que era muy satisfactorio el estado de la instrucción de los niños de las secciones superiores.

Nada me consta, por otra parte, respecto a la especie de que el Maestro haya vivido vida íntima con su anterior criada; pero, por más que considere posible que el hecho tuviese visos de certeza, toda vez que mi antecesor en el cargo 
parroquial ha gestionado, al parecer, con éxito para que cesasen los motivos de tales murmuraciones, creo que no debe fundarse en ello causación alguna, por tratarse de un hecho no probado y de fecha atrasada, siquiera en gracia de que el Sr. Calvelo se prestó a separar de su lado a la sirvienta con quien se le censuraba.

Tampoco considero exacto que la Madre del acusado se haya separado de éste por efecto de las irrespetuosidades y malos tratamientos de que, dicen sus enemigos, era objeto por parte de la criada, y aun por la de él influido por ésta.

Y me consta por último que, bien a pesar suyo, no vive el Maestro con su esposa. Él la recibiría con los brazos abiertos; pero ella resiste el volver a la vida conyugal, $\mathrm{y}$, antes de ahora, ha presentado demanda de divorcio que fue desestimada por el Tribunal Eclesiástico.

Concluiré repitiendo mi afirmación primera: los que acusan al Maestro obran a impulso del odio que por él y por sus amigos, más que por él, sienten: no por amor a la verdad ni por el interés del bien público. Y en prueba de la exactitud de este aserto, enteraré a V. de un particular que puede comunicar al Sr. Rector.

Mi coadjutor, D. Nicolás García, se me presentó en uno de los días anteriores al en que debía prestar declaración en el expediente para que le dijese como había informado yo, pues no quería ponerse en contradicción conmigo. -Como he informado, le contesté, ya lo sabe V. Dije que nada me constaba en contra ni de la moralidad ni del comportamiento profesional del Maestro. Si a V. le consta algo y lo declara, no por eso estaríamos en contradicción. ¿A V. le consta algo?

-De antes, sí, me dijo, aludiendo con la palabra antes al pretendido amancebamiento del Maestro con la criada, pero de ahora, no; y si declaro contra él, es para vengarme.

-No está bien, le observé, que el Sacerdote que predica el perdón de las injurias se vengue de ellas. Le hice además otras reflexiones y me pareció que al despedirnos llevaba el propósito de ajustar su declaración a la verdad. Pero después supe que se había dejado llevar de su resentimiento.

Terminó el Sr. Cura manifestándome que tanta menos fe le merecían los principales acusadores del Maestro al atribuirle vicios morales, cuanto algunos de ellos estaban muy lejos de ser dechados de moralidad.

Di gracias a mi digno interlocutor por sus nobles explicaciones y me retiré.

Pudiera muy bien ante tan desapasionado y autorizado informe prescindir de procurarme otras noticias. He visto, sin embargo, a otras personas no menos respetables, quienes coincidieron con el párroco en la apreciación de las condiciones del Maestro y de los móviles a que obedecen sus acusadores.

Y concluí recibiendo una información, que acompaño, de padres o encargados de niños que continúan concurriendo a la Escuela a pesar de la propaganda hecha 
para que quedase desierta. En dicho documento se ven confirmados los anteriores favorables informes respecto al Sr. Calvelo sin que ni uno solo de los declarantes haya atestiguado la certeza de las acusaciones.

Entiendo pues sobradamente fundado el juicio que al principio de este informe he emitido acerca de D. Hermenegildo Calvelo. Estoy plenamente convencido de que son infundadas las acusaciones contra él hechas y que no tienen otra razón de ser más que el resentimiento en sus acusadores producido por haber intimado relaciones con la autoridad local y con las personalidades afectas a ésta.

Y no obsta a mi convicción el estado de la Escuela que encontré poco satisfactorio, sin que al exponer este juicio entienda que no ha estado exacto mi digno compañero el Sr. Inspector de Pontevedra en el [informe] que emitió acerca de la misma Escuela en Julio del año último. Nuestra aparente contradicción tiene una explicación sencilla. Yo no encontré en la Escuela a los alumnos de las secciones superiores, $6^{\mathrm{a}}, 7^{\mathrm{a}}$ y $8^{\mathrm{a}}$. Se había suspendido recientemente de empleo al Maestro propietario y los amigos de éste han procurado entonces que dejaran de asistir aquellos para que con su aventajada instrucción no pudiesen engalanarse los perseguidores de Calvelo, atribuyéndola al sustituto.

En cambio de estos niños habían vuelto al establecimiento algunos de los que por gestiones de los mismos perseguidores lo habían dejado antes para ir a poblar las Escuelas privadas, en las que olvidaron lo poco o mucho que sabían, y adquirieron resabios en su instrucción, que costará tiempo hacerles perder.

Tampoco obsta a la misma convicción la instancia acusadora que por testimonio notarial se ha presentado suscrita al parecer por crecido número de personas. No es más que una nueva manifestación de la malevolencia con que determinadas personas tratan de causar irreparables daños al Maestro y del desenfado con que para conseguir sus fines se sirven de toda clase de medios, aun de los que reprueba toda conciencia honrada.

Dicha instancia debe ser tomada en consideración; pero sólo para que los Tribunales de Justicia entiendan en ella.

Yo no he podido darme razón del por qué sus autores se han propuesto a presentarla por medio de testimonio y he llegado a conjeturar si acaso les convendría obrar así para ocultar alguna mixtificación.

No estaría por tanto de más que los Tribunales comprobasen la autenticidad de las firmas originales, y ratificasen a sus autores, deduciendo luego las responsabilidades que resultasen de estas diligencias.

Sería conveniente también que previa dicha ratificación persiguiesen los mismos Tribunales el perjurio cometido por los al parecer firmantes de la referida instancia José Lajos, Andrés Ferradáns y Modesto Garrido, que por medio de tal 
documento se han retractado de lo que bajo juramento habían declarado ante el Alcalde en ocho de Octubre los dos primeros y en diez del mismo mes el tercero.

Deben además ocuparse en la persecución de los asuntos contrarios a la verdad, injuriosos además y de los que alguno pudiera ser calumnioso, en este período de la instancia: "El citado Inspector (el de Pontevedra) en unión de este Ayuntamiento, o mejor aún, de las contadas personas que en Cuntis protegen al Maestro, instruyeron una farsa de expediente en la cual no se oyó a los que iban resueltos a decir la verdad, atemorizándolos para esto, y en cambio depusieron algunos que para que V. E. vea la libertad que tenían para declarar firman esta instancia acusando al Maestro...".

Y resulta que el Inspector no ha intervenido en la instrucción del expediente, pues las informaciones testificales que aún lo constituyen fueron recibidas en Septiembre y Octubre y aquel estuvo en Cuntis en Julio para visitar la Escuela: Que tampoco intervino en él el Ayuntamiento, pues fueron recibidas las informaciones por el Alcalde asistido del Pror. Síndico y del Secretario de aquella Corporación: Y que en la segunda información recibida en Octubre y en la que debían declarar las personas citadas en el informe del Juez municipal solo dejaron de hacerlo por no haber sido llamados D. Manuel Ballesteros y D. Manuel Barreiro que no están domiciliados en el Distrito, y el Párroco de Cuntis y los Srs. D. Joaquín Gómez Losada, D. Enrique Campos Aboy y D. Antonio Rivas Sueiro, que habían informado o declarado con juramento en el mes de Septiembre.

Procede también que ante la muy censurable falta de seriedad de los Vocales de la Junta local de $1^{a}$ enseñanza D. Manuel Villar y D. José García Sueiro, que después de suscribir el dictamen unánime favorable al Maestro emitido por la misma Junta, aparecen firmando la instancia testimoniada que es la contradicción de aquél, se les destituya del cargo de vocales de aquella corporación si se ratificasen en lo que expresa su última manifestación.

Dicho esto, casi está por de más consignar mi opinión de que debe alzarse la suspensión impuesta al Maestro y sobreseer el expediente contra él instruido por ser infundadas las acusaciones de que fue objeto.

Pero si esto demanda la justicia y el buen nombre de D. Hermenegildo Calvelo, otros intereses tan respetables y sagrados aconsejan que se traslade a este a otra Escuela.

El Sr. Calvelo, al publicar en un periódico de Pontevedra una serie de artículos depresivos para sus cinco principales perseguidores ha incurrido en grave desacierto que a mi juicio le hace incompatible con no pequeña parte del vecindario de Cuntis. En esos artículos, convertido de acusado en acusador, ha dado publicidad a hechos que más tienen que ver con la vida privada que con la pública de las personas en ellos nombradas. Éstas, que son influyentes en la localidad y arrastran muchas voluntades, podrían acaso perdonar y aun 
olvidarían su fracaso en el expediente que han promovido al Maestro, pero no olvidarán ni perdonarán a éste que haya tratado de rebajarles en la consideración pública, y este resentimiento les llevará a dificultar y amargar por todos los medios a su alcance la vida oficial de su detractor y para [a] minar su ascendiente y su prestigio.

Y esto tiene que redundar forzosamente en daño de la enseñanza, cuyos frutos habían de resentirse de la insanidad de la atmósfera en que aquella viviese.

Creo por lo mismo que se impone la necesidad de pedir la traslación del Señor Calvelo a otra Escuela de igual clase y sueldo, pero declarando que esta traslación forzosa no ha de perjudicarle en sus progresos y adelantamientos en la carrera por cuanto se dicta por las conveniencias del servicio.

Es cuanto tengo que informar a V. E. rindiendo culto a la verdad y en desempeño del cometido que ha tenido a bien confiarme.

Dios guarde a V.E. m. a.

La Coruña, 20 de Enero de 1895

Tomás Luciano Carreira

\section{Documento 3. Contestación ao prego de cargos dirixida polo mestre á Xunta provincial de Instrucción pública de Pontevedra}

Antes de contestar en detalle y de manera precisa a cada uno de los cargos que V. I., en cumplimiento de lo acordado por el Ilmo. Sr. Rector, se dignó remitirme, ruego a V. I., y a la Ilma. Junta provincial que tengan a bien dispensarme la gracia de fijar su ilustrada y superior atención en algunas observaciones que considero necesarias y muy pertinentes; ya porque demuestran la pertinaz e inconcebible pasión con que unos cuantos, muy pocos, vecinos de esta villa me persiguen, ya porque ellas por sí solas y sin necesidad de ulterior prueba (que ofrezco, sin embargo, y plena, y como más justificada la desee V. I.) bastan, no sólo para sincerarme por completo, sino para acusar a mis acusadores.

El gran número de personas de diferentes clases y condiciones que depusieron e intervinieron en la información que acerca de mi conducta moral y profesional se abrió, de orden y mandato del Ilmo. Sr. Rector; el exceso mismo de animosidad que contra mí manifestó el Sr. Juez municipal de Cuntis, Sr. Joaquín Barreiro y sus parientes, y la circunstancia de que el Ayuntamiento haya acordado en 17 de marzo último denunciar, como así lo hizo, en el Juzgado de instrucción de Caldas a 65 vecinos del distrito, acusándolos de haber cometido los delitos de falsedad, injuria y calumnia graves en una queja autorizada por Notario que suscribieron contra mí, facilitáronme el conocimiento de esta queja, del informe emitido por el Sr. Juez municipal, y de algunos otros antecedentes que obran en la información. 
La falsedad de las aserciones que sirven de base a la queja constan claramente en el expediente incoado, y por lo tanto, lejos de servir, ni siquiera de pretexto, para hacerme cargo alguno, lo único que prueban es la sinrazón y falta de conciencia de los que la suscribieron y la malquerencia y el odio que me tienen las pocas personas que la promovieron.

Se afirma en ella que el Sr. Inspector de la provincia obró parcial e injustamente, y en unión con el Ayuntamiento instruyó una farsa de expediente. En el expediente consta que ni el Inspector ni el Ayuntamiento tomaron parte en él. Ningún individuo del Ayuntamiento conoce ni tuvo jamás relaciones de ningún género con el Sr. Inspector, hecho que demostraré cuando en la información que se abra me justifique de los cargos que se me hacen. El Sr. Inspector se limitó a girar visita en 16 de Julio de 1894, y la información testifical la recibieron, de orden superior, en Septiembre y Octubre del mismo año, no el Ayuntamiento, sino los señores Alcalde y Síndico.

Se asegura en la queja que la autoridad municipal no oyó a testigos que se presentaron dispuestos a declarar la verdad. En el expediente consta que fueron oídas todas [las] personas que ofrecieron su testimonio, incluso las citadas, en contra mía, por el Sr. Juez municipal.

Se añade, que se atemorizó a algunos para que declarasen en mi favor. Es bien extraño que siendo veinte, lo menos, los que han depuesto o informado, ninguno se haya quejado ni reclamado contra la supuesta coacción. Es además verdaderamente extraordinario, por lo extravagante y no visto, que se presentasen a deshora unos cuantos labriegos, en su inmensa mayoría, acusando a respetables autoridades administrativas de haber prevaricado, y de debilidad (por haberse dejado atemorizar y cohibir) al Sr. Cura párroco, a tres señores Presbíteros, al médico municipal, a un Licdo. en Farmacia, a un abogado, al médico y Fiscal municipal, a un veterinario facultativo y a comerciantes y propietarios. Paréceme que ningún argumento puede hacer resaltar mejor la absurdidad de la acusación como la singularísima osadía de los acusadores. Al Sr. Inspector de la provincia de la Coruña, Sr. Carreira, he oído, por incidencia, cuando, de orden del Ilmo. Sr. Rector, vino a Cuntis, elogiar el celo con que los señores Alcalde y Secretario del Ayuntamiento le facilitaron los medios de cumplir su cometido. Dicho señor Inspector recibió también en Cuntis una pequeña información testifical, ¿habría en ella coacciones, farsas, terrores, en una palabra, prevaricación?

El testimonio de los firmantes de la instancia o queja notarial no puede tener valor alguno. Porque -ofrezco probarlo-, $1^{\circ}$ Ninguno, excepto dos o tres, tiene hijos que puedan recibir enseñanza en la escuela de mi cargo. $2^{\circ}$ Algunos distan de la capital del centro escolar una legua, lo menos, de camino escabroso y casi impracticable durante el invierno, y de los lugares de su residencia jamás hubo alumnos matriculados en la escuela de niños ni en la de niñas. $3^{\circ}$ Las declaraciones de otros, entre ellos D. José García y D. Manuel Villar, individuos de la Junta local 
[de enseñanza primaria], contradicen a las que prestan en la queja. $4^{\circ}$ El testigo instrumental y de conocimiento, D. Laureano García Rodríguez, no es vecino ni está domiciliado en Cuntis, y por vivir hasta hace poco en un pueblo lejano, en la provincia de la Coruña, es moralmente imposible que conozca a todos os firmantes. $5^{\circ}$ Ninguno de los firmantes, a excepción de la familia de los Sres. Barreiro -el Sr. Inspector de Pontevedra se hospedó en su casa, cuando vino a Cuntis- conoce a dicho Sr. Inspector, ni sabe cuándo vino a Cuntis, ni cuándo se recibió la información, ni pueden seguramente determinar las personas que en ella depusieron, y muchísimos menos si sobre ellas se ejerció o no coacción. $6^{\circ}$ Por la distancia de su vecindad y la falta de trato -algunos ni de vista me conocen- [no] pueden afirmar, como lo hacen, si cumplo o no mis deberes profesionales, ni el género de vida que llevo, y con menos razón atribuirme, como me atribuyen, actos de loco y deudas. $7^{\circ}$ En las declaraciones que están actualmente recibiéndose en el Juzgado de instrucción de Caldas, en virtud de la denuncia o querella citada del Ayuntamiento, ninguno de los 65 firmantes dice que haya suscrito queja alguna, en la que atribuyesen al Sr. Inspector de Pontevedra o al Ayuntamiento de Cuntis actos injustos, farsas, terrores ni coacciones. De lo cual se deduce que o fueron sorprendidos y engañados por alguien, o que mienten y se desdicen; y por lo tanto, que sus declaraciones no acreditan ni atesoran otra cosa que su ignorancia y mala fe. $8^{\circ}$ Casi todas las personas citadas en su informe por el Sr. Juez municipal, y que por mandado de la Ilma. Junta provincial declaran en el expediente, deponen lo contrario de lo que se propusiera el Sr. Juez, al citarlas. $9^{\circ}$ Los firmantes, que todo el pueblo acusa como promotores de la queja y de mi persecución, D. Joaquín Barreiro y D. José Fariña son primos y cuñados. D. Ramón Barreiro es hermano del D. Joaquín. D. Eugenio Aboy es pariente de ellos, y yo además en una contienda judicial me vi obligado, de acuerdo unánime con otros tres Peritos, a informar en contra de lo que el Aboy juzgaba su derecho. El presbítero D. Nicolás García Garrido es también pariente de los Barreiro. Nuestro Excmo. Prelado acaba estos días de privar a este señor presbítero de una capellanía, y de imponer la pena de suspensión al otro señor presbítero firmante de la queja, Don Pedro Castro Rivas, que se atrevió a celebrar el santo sacrificio de la Misa, a pesar de la prohibición del venerable Prelado, según de público se asegura, incurriendo por este motivo en irregularidad; antecedentes muy dignos de tener en cuenta, para apreciar el valor de las declaraciones de los dos presbíteros, que en esta ocasión se separaron de la conducta seguida por su señor Cura párroco y por todos sus compañeros en el sagrado ministerio sacerdotal. Ninguno de estos señores, excepto el Aboy, tiene hijos en condiciones de recibir enseñanza en mi escuela. $10^{\circ} \mathrm{La}$ declaración prestada por D. José Fariña en el expediente, según de público aseguran sus amigos más íntimos, lejos, por su exageración y apasionamiento, de perjudicarme, me favorece; pues afirma en ella hechos verdaderamente inconcebibles. Para hacer de algún modo verosímiles los hechos declarados, era necesario suponer más tarde que yo ejecutaba actos de loco. 
También existe en el expediente una instancia de un tal D. José Lorenzo, que se dice Párroco en América. En ella pide al Ilmo. Sr. Rector, nada menos, que el envío de un nuevo maestro que se encargue de enseñar a cinco o seis niños que dicho señor ha adoptado, prohijado, o de los que bondadosamente se encargó. El Sr. Lorenzo no puede adoptar porque no tiene la edad que señala el art ${ }^{\circ} .173$ del Código civil, ni el art ${ }^{\circ}$. 174, de conformidad con nuestras antiguas leyes, especialmente con lo dispuesto en la ley 3, título 22, libro 4 del Fuero Real, permite a los eclesiásticos el derecho de adopción.

Tampoco debe estar encargado de los niños, porque, claro es, que si vive de tránsito en Cuntis, como afirma en la instancia, y muy luego ha marchar a América, en donde es Cura ecónomo o Vicario, tiene que traspasar el encargo a otra persona, si los niños han de recibir enseñanza en la escuela de mi cargo. Por este endose o traspaso (de todo punto necesario) de niños, puede juzgarse indiciariamente de la sinceridad de las aserciones del Sr. Lorenzo, contra quien, a mi juicio, ha de resultar algo grave y de inmediata responsabilidad en la información que se abra para refutar yo los cargos que se me dirigen. Los niños prohijados o sometidos a la dirección del Sr. Lorenzo no existen sino en la instancia que el Sr. Lorenzo se atrevió a dirigir al Ilmo. Sr. Rector.

Hechas estas declaraciones que, en justa defensa y a fin de aclarar, en lo que de mi parte esté, la odiosa intriga de que estoy siendo víctima, me considero obligado a exponer, paso a contestar a cada uno de los cargos.

\section{Al $1^{\text {er }}$ cargo}

Nunca, a ninguna hora, ni de día ni de noche, he frecuentado la taberna de José de la Fuente. Este señor es dueño de un Café, único que existe en Cuntis, en el que paréceme que he visto al Sr. Inspector el día que vino a Cuntis, y cuya existencia tal vez conozca también algún Sr. individuo de la Ilma. Junta provincial [de Instrucción pública]. A este Café, en el que he visto, durante la temporada veraniega de baños, a innumerables personas de Galicia y de otras provincias (recuerdo en este momento al Sr. Juez de $1^{\text {a }}$ instancia de Caldas, D. Benito Sánchez, al actuario de la misma villa, Sr. Martelo, al abogado D. Adolfo Mosquera, al médico de los balnearios Sr. Casulleras, al catedrático de la Universidad de Santiago D. Alfredo Brañas); a este Café concurro yo desde un poco después de anochecido hasta las diez o diez y media de la noche, como en otro tiempo concurrían, con objeto de tomar café o jugar al billar o al tresillo el Sr. Juez municipal D. Joaquín Barreiro y sus señores hermanos; y como concurría, hasta no hace mucho, algunas veces, con el mismo objeto, el presbítero D. Nicolás García Garrido. Juzgo que no debe estarme prohibido frecuentar un Café público a las mismas horas en que lo frecuentan abogados, médicos y presbíteros.

Dícese en el cargo que muchas veces salgo de la taberna de José de la Fuente contento. Podía negar en redondo la verdad del cargo, y probar la negativa; porque 
en la taberna de José de la Fuente no entro ni salgo, ni he salido ni entrado nunca. Más suponiendo que por la palabra taberna se entienda Café, y por la palabra contento quiera expresarse algo así como excitado por alcoholes, resulta del contenido literal del cargo mismo que no soy borracho, porque de ningún borracho se dice que esté contento. Con todo, ofrezco probar, y la prueba bien fácil es, la falsedad del cargo.

Añádese que "continúo en la actualidad el mismo género de vida en el Café de D. Antonio Rivas Sueiro", cosa de todo punto imposible, porque el Sr. Rivas Sueiro no tiene, como se probará, Café abierto sino durante la temporada de baños, y reside el resto del año en la ciudad de Pontevedra.

\section{Al $2^{\circ}$ cargo}

Por muy amargo que me sea hacer relaciones dolorosísimas de mi vida íntima y de familia, necesito vindicarme de una manera plena y perfecta, sin dejar el menor resquicio de duda, del cargo que se me dirige, asegurando "que vivo separado de mi esposa, a la que tengo completamente abandonada."

En junio de 1880 contraje matrimonio con la Sra. Da Manuela Villanueva y García, viviendo con ella desde entonces en la mejor harmonía hasta el 16 de Febrero de 1889. En Diciembre de 1888 falleció mi buen padre -q. e. D. e.- en la villa de Arzúa, viniendo mi señora madre a vivir con mi esposa y conmigo a la ciudad de Santiago, en donde residíamos. El 16 de Febrero siguiente desapareció mi esposa de nuestra casa, sin hacerme la más ligera indicación de sus proyectos, y pidió al Juzgado de $1^{a}$ instancia de Santiago el depósito personal para entablar demanda de divorcio, que interpuso en el Provisorato el 6 de Abril del mismo año de 1889.

A pesar de los esfuerzos que hice presentándole todos los medios de posible avenencia, incluso el de separación amistosa ad tempus, ya directamente, ya por medio de su distinguida y virtuosa familia, del P. Jesuita Minasi-hoy fallecido-, del Sr. Párroco de San Juan D. Vicente López Vigo, del catedrático de la Universidad D. Alfredo Brañas, de la sobrina del Sr. Cura de Salomé señorita $\mathrm{D}^{\mathrm{a}}$ Carmen Adrán y de las señoritas $D^{a}$ Victoriana, $D^{a}$ Manuela y $D^{a}$ Mercedes Devesa, y de otras muy dignas y respetables personas, mi esposa rechazó siempre con violencia, y durante más de tres años, todos los medios de reconciliación que se le propusieron. Personas muy doctas opinan que la terquedad y obstinación de la $\mathrm{D}^{\mathrm{a}}$ Manuela, negándose a todo arreglo amistoso conmigo, débese a un estado de excitación hesteriforme en que se encuentra, estado que, atendida la edad de la paciente -va a cumplir 52 años- reputan incurable.

Como la $\mathrm{D}^{\mathrm{a}}$ Manuela no instase, desde que presentara en 6 de Abril de 1889 la demanda de divorcio, el curso de ésta, solicité del Provisorato en 4 de Junio siguiente que se la obligase a presentar las pruebas, por lo menos de indicios 
racionales, que se exigen en el antejuicio previo necesario para decretar la admisión de las demandas de divorcio. El Sr. Provisor accedió a mi ruego y el día 5 mandó al Sr. Vice-Cura de San Fructuoso, Don Andrés Calo Brage, que intentase la reconciliación que previene el derecho. En 10 de Junio del mismo año (En 10 de Junio del mismo año) el Sr. Calo ofició al Provisorato, y en oficio que obra en el expediente hace constar que yo me avine a la reconciliación, pero que la " $\mathrm{D}$ a Manuela se negó en absoluto a toda avenencia, manifestando que estaba resuelta a no volver a reunirse nunca jamás con su marido.” El 14 siguiente el Sr. Provisor concedió a la $\mathrm{D}^{\mathrm{a}}$ Manuela 20 días de término para presentar la prueba testifical. Transcurridos los 20 sin que hubiese hecho la citación de testigos, le fueron concedidos otros diez días más. Citó, al cabo, como testigos, entre otras personas, al Beneficiado de la S. I. Catedral, D. José Rivademar, a la hermana de este señor, $D^{a}$ Flora, a una sobrina y a la criada de esta familia, Manuela Cardama. También citó y declaró Teresa Barroso, que nos sirviera durante más de dos años. Todas estas personas, en efecto, podían mejor que nadie declarar en la demanda, habitaban la casa que nosotros habitábamos en la Plazuela de S. Martín n ${ }^{\circ}$, y con nosotros acababan de vivir durante cinco años por lo menos.

El día 22 solicitó la ampliación de prueba que le fue concedida, y presentó como testigos, entre otros, al abogado y notario D. Jesús Fernández Suárez, al médico D. Juan Barcia y a una su amiga llamada Ramona Lens. El día 31 pidió nueva ampliación de prueba, que no le fue concedida por estimar el Sr. Provisor que desde el 6 de Abril de 1889 en que presentó la demanda de divorcio hasta el 31 de Julio del mismo año había tenido la demandante tiempo sobrado de proponer todas las pruebas imaginables; y que, tratándose de juicios sumarísimos no procede, sin burla de la ley, estar concediendo a todas horas nuevos plazos y ampliaciones.

Pasó el expediente a informe del Sr. Fiscal eclesiástico, que lo era a la sazón el que es hoy Magistral de la S. I. Catedral de Santiago, D. Severo Araujo, y en 4 de Agosto el Fiscal emitió dictamen, en el que dice que no considera admisible la demanda, porque "hay testigo que nada absolutamente depone, los hay que deponen a favor del demandado, y los que algo dicen lo han sabido por oírselo a la misma demandante, según confiesan."

El 12 del mismo mes y año el Sr. Provisor, conformándose con el dictamen fiscal, dictó Auto de no haber lugar a la demanda. El 17 siguiente apeló de este Auto al Supremo Tribunal de la Rota, apelación que le fue concedida con ambos efectos el día 21.

En las demandas canónicas el curso de las apelaciones corre a cuenta y cargo de la parte actora durante un tiempo improrrogable y fatal, transcurrido el que, las demandas pueden ser declaradas desiertas, y a los efectos legales son como si no se hubieran interpuesto. Y como la demandante dejó pasar casi tres veces más tiempo que el marcado por el derecho canónico sin pedir siquiera el curso de la 
apelación, el Sr. Fiscal eclesiástico en 2 de Noviembre del mismo año recurrió, en cumplimiento de su deber, al Provisorato pidiendo la declaración de desierta para la demanda. En su oficio, el Sr. Fiscal, dice que "la demandante ha renunciado a la apelación, o dicha apelación no fue otra cosa que un medio más o menos estudiado para burlar los efectos de la ley." El Sr. Provisor, en vista de la petición fiscal, declaró desierta la apelación en 5 del mismo mes. El día 9 pidió la $\mathrm{D}^{\mathrm{a}}$ Manuela la reposición del Auto, que le fue denegada el 11.

En 5 de Noviembre de 1889 el Sr. Juez de $1^{\mathrm{a}}$ instancia del partido de Santiago, en vista de testimonios expedidos por el Provisorato, dictó Auto alzando a $\mathrm{D}^{\mathrm{a}}$ Manuela el depósito personal, y mandando que se restituyese a la casa de su marido, de cuyo Auto apeló a la Excma. Audiencia de la Coruña, que confirmó lo dictado por el Juez inferior -por caducidad- a últimos de Marzo de 1894, si no estoy equivocado en la cita de la fecha.

El 23 de Noviembre de 1889 el mismo Juzgado sentenció que no había lugar a los alimentos provisionales que la $\mathrm{D}^{\mathrm{a}}$ Manuela pidiera. De la sentencia también apeló el día 28. En 26 de Mayo de 1890 la Audiencia confirmó la sentencia del juzgado.

Ni en las demandas de depósito personal ni en la de alimentos me personé ante la Audiencia de la Coruña.

El Sr. Cura de San Juan, D. Vicente López Vigo, le propuso en mi nombre el divorcio más completo y decoroso que ella pudiera desear, a saber, que se sometiese a las condiciones que exige el derecho canónico y a las que considerase convenientes la Iglesia, y me permitiese recibir órdenes sagradas. Accedió al principio, pero luego se negó a ello en absoluto. Acerca de este hecho pueden deponer el citado Sr. López Vigo y el actual Rector del Seminario Conciliar, D. José Lavín.

El actual Sr. Párroco de Cuntis, D. Isolino Suárez, espontáneamente y sin decirme nada, escribió hace poco a mi esposa, aconsejándola una reconciliación conmigo. Mi sra. esposa le contestó negándose a la reconciliación en forma desatenta. En cambio le escribiera antes, con mucha deferencia y atención, rogándole que procurase obtener de mí para ella recursos pecuniarios.

Resulta, pues, a mi juicio, evidentemente probado, si la relación de hechos por mí expuesta es verdadera, que no soy yo el que vive separado de mi esposa, sino que ella es la que vive separada de mí; que no soy yo el que la tiene abandonada, sino que es ella la que me tiene abandonado a mí.

Para comprobar con matemática exactitud la verdad de los hechos por mí expuestos, ruego con todo encarecimiento a V. I. que tenga a bien pedir a los centros y dependencias respectivos las compulsas literales o en relación de los documentos y demás datos por mí citados, y que, si me es permitido, reclamo para que se unan al expediente. Y a fin de que esta mi petición pueda con más 
facilidad ser cumplida y satisfecha por la justificación de V. I. diré que la demanda de divorcio se tramitó en el Provisorato por la Autuaría [sic] de D. Tomás Acosta, que regentaba D. Luis Casal, y las demandas de depósito y de alimentos por las Autuarías [sic] respectivas de los señores Neira y Leal.

Se afirma también en este segundo cargo que mi sra. madre tuvo necesidad de dejar mi compañía, en la que no podía dignamente vivir, y establecerse (y establecerse) en el lugar de Rajos [Rojos].

Mi señora madre, por motivos de salud y afecciones de amistad, fue en dos o tres distintas ocasiones a pasar temporadas, más largas o más cortas, no a Rajos [Rojos], sino a Bertamiráns, en la parroquia de Ortoño. Ella declarará en la información, y su declaración ha de ser de seguro muy interesante. Por ahora me limito a afirmar que mi anciana madre, por sus virtudes, porque es la única persona de mi familia que conozco, y por los cuidados que siempre me ha dispensado con entrañable afecto, merece y siempre mereció todos mis respetos y todo mi cariño.

\section{Al $3^{\text {er }}$ cargo}

Ofrezco la prueba de que es calumnioso, con el testimonio de los vecinos. Fácil es organizar cencerradas, sobre todo en las aldeas. Yo no puedo ser responsable de actos indebidos ejecutados por otros. Aunque esa cencerrada imaginaria hubiera tenido realidad, yo no soy responsable de ella, sino, en todo caso, de los motivos que la hubiesen ocasionado. Y como los motivos no lo determina el cargo, puedo y debo suponer que serán los contenidos en los cuatro restantes. Por lo tanto, refutados éstos, queda por ende refutado este $3^{\text {er }}$ cargo.

\section{Al $4^{o}$ cargo}

Es absolutamente imposible que con un abandono tan grave y tan continuado en la enseñanza los niños estubiesen [sic] tan adelantados, tratándose principalmente de un país en que la concurrencia a la escuela es irregular, y cuando hay trabajos de campo casi nula. Hoy mismo, de 65 alumnos matriculados no asistieron a la clase de la mañana más que 8 y a la de la tarde 5 .

Respecto de la enseñanza informarán los sres. Inspectores.

Es también absolutamente imposible que en un país tan fatigado como este por intrigas de la llamada política rural, y que yo no sé como llamar, no se me hubiese formado hasta ahora expediente, y que precisamente ahora se quejen de mí, no los padres de familia, sino personas que no tienen hijos o no los tienen en condiciones de recibir enseñanza en la escuela, por diferencias de sexo o por exceso o defecto de edad.

Mi descuido y abandono no pudo tampoco dar motivo a que ningún "padre de familia enviase sus hijos a escuelas particulares." No existen en Cuntis escuelas 
particulares, sino locales sin ninguna condición pedagógica ni material de enseñanza, en cuyos locales unos cuantos hombres y mugeres [sic] que carecen de la más vulgar cultura e instrucción, se dedican a enseñar los principios de lectura y la práctica rutinaria de la escritura. Así lo reconoció el Inspector que fue de esta provincia Sr. Soriano. El Sr. Inspector de la Coruña D. Tomás Luciano Carreira que visitó detenidamente las principales escuelas particulares de este distrito escolar puede emitir concienzudo informe, y a lo que él diga me atengo.

\section{Al $5^{\circ}$ cargo}

Pasa de tres años que unos seis vecinos procuraron deshonrarme en el concepto público atribuyéndome las acciones más vituperables. Durante el verano procuran que las personas, algunas de mucha consideración social, que concurren a sus fondas formen de mi conducta las ideas más odiosas. Vine sufriendo este largo tiempo tanto como puede sufrir, según el dicho vulgar, un maestro de escuela. No satisfechos con que se me formase expediente gubernativo, acudieron a últimos del verano próximo pasado al periódico católico que, con el título de "El Pensamiento Galaico", se publica en Santiago, deprimiéndome en un escrito que el abogado y notario D. Jesús Fernández y Suárez calificó de asqueroso. El director del citado periódico D. Ramón Gallego se negó en absoluto a insertar el comunicado. De este hecho pueden dar testimonio los señores Fernández Suárez y Gallego y el presbítero de Cuntis D. Enrique Campos.

No pude resistir más tiempo, y publiqué en "La Unión Republicana", de Pontevedra, unos cuantos escritos, en los que trataba, no de hechos privados, sino de actos públicos ejecutados por los que considero mis perseguidores.

Ni desde el punto de vista moral ni desde el punto de vista legal juzgo censurable este hecho. Pienso que mi cargo de maestro no me impide hacer uso de un derecho que las leyes fundamentales y las orgánicas del Reino conceden al más ruin de los españoles. Maestros de escuela han censurado en la prensa a Ministros y Directores generales de instrucción pública. Yo mismo, siendo empleado en la Secretaría gral. de la Universidad publiqué en la "Gaceta de Galicia" unos ocho o diez artículos criticando algunas teorías sustentadas en "El Regionalismo", uno de los más famosos libros del sabio catedrático de aquella Universidad D. Alfredo Brañas; y ni el Sr. Rector me lo impidió ni el Sr. Brañas se quejó. El Sr. Becerra, siendo Ministro de Ultramar, declaró no hace mucho en el Congreso que escribiera al Sr. Calleja, Capitán general de Cuba, que tratase a los periódicos separatistas con mesura y liberalidad, porque en los países libres la libertad de la prensa es cosa sagrada. ¿Y no he de poder yo, desde que llegué a maestro de escuela, invocar mis derechos de ciudadano español y publicar en un periódico hechos públicos relacionados con intereses de la localidad en que vivo, si los ejecutan unos cuantos oscuros fondistas, un abogado y dos presbíteros a quienes nuestro Excmo. Prelado acaba corregir severamente? ¿Y no he de poder hacerlo, aun cuando estos señores 
me acusen, me persigan de todos modos y apelando a todos los medios, y me expedienten, y me procesen en los tribunales ordinarios, y den ocasión para que se me haya tenido suspenso de empleo y medio sueldo más de tres meses? La Ilma. Junta provincial decidirá. Y por última observación le ruego que se digne fijar su atención en la R. O. de 20 de marzo de 1885 dictada por el Excmo. Sr. Ministro de Fomento D. Alejandro Pidal, uno de los señores Ministros que tienen criterio más estricto y riguroso en materia de libertad de prensa.

Espero que V. I. y la Ilma. Junta provincial, que por la ley son los defensores de los derechos y de la dignidad de[1] magisterio, han de facilitarme todos los medios de justificación e interesarse vivamente en el pronto esclarecimiento de los hechos que acabo de referir.

Y puesto que hay quejas de que el Ayuntamiento ha obrado parcialmente en mi favor, ruego a V. I. que se digne disponer que sean recibidas las pruebas que ofrezco en el Juzgado municipal de Cuntis, o ante la autoridad que V. I, considere más conveniente, reservándome el derecho de citar testigos y de intervenir personalmente en la información formulando interrogatorios y haciendo preguntas a los declarantes.

Y como tengo la convicción de que en el expediente que obra en las oficinas de esa Ilma. Junta existen manifestaciones gravemente penables, espero también de la justificación de V. I. que ha de tener a bien acompañar, con sus órdenes al Juzgado municipal de Cuntis, dicho expediente original, a fin de que pueda yo enterarme detenidamente de él, y exigir en su día la responsabilidad consiguiente ante los tribunales ordinarios.

De la rectitud probada de V. I. y de la Ilma. Junta provincial, que siempre se distinguió por su celo en favorecer la enseñanza primaria y amparar a los encargados de ella, espero también que, si constan con evidencia en el expediente hechos dignos de castigo procederá de plano adoptando las medidas más eficaces para evitarme nuevos disgustos y sinsabores inmotivados, y contener, en lo posible, la saña tan cruel como pertinaz de mis perseguidores.

Es cuanto tengo el honor de exponer y pedir con la mayor consideración y respeto a V. I. y a la Ilma. Junta provincial.

Dios guarde a V. I. m. a. Cuntis 12 de junio de 1895

Hermenegildo Calvelo

\section{Documento 4. Informe do inspector de Pontevedra á Xunta provincial de Instrución pública}

Examinadas con atención las nuevas diligencias practicadas en el expediente que se instruye a Don Hermenegildo Calvelo, maestro de la escuela completa de niños de Cuntis, por supuestas faltas profesionales y morales. 
Visto el resultado que arrojan las que llevó a cabo, de orden del Ilmo. Sr. Rector de Santiago, el Inspector de $1^{\mathrm{a}}$ enseñanza de la Coruña.

Visto igualmente el de las que instruyó el vocal-delegado de la Ilma. Junta provincial, y las del Exjuez de Cuntis, Don Manuel Castro y Gil.

Vistos también los descargos que, para probar su inocencia, aduce el maestro Sr. Calvelo.

Considerando que, a juicio del que suscribe, no se prueban de una manera concluyente los cargos que se atribuyen al Sr. Calvelo.

Considerando que, algunos, como el sacerdote Don José María Lorenzo, se contradicen en sus declaraciones.

Considerando que, al negarse los acusadores a prestar declaración ante la autoridad designada, es indicio de que han incurrido en manifiesto error, o cuando menos, que no tienen seguridad en las afirmaciones que anteriormente han hecho; $\mathrm{y}$, finalmente,

Teniendo en cuenta que, así como los acusadores del Sr. Calvelo se atreven a atribuir al que suscribe actos que, ni solo, ni en unión del Ayunt ${ }^{\circ}$ de Cuntis ha ejecutado, como lo prueba este mismo expediente, hay que suponerlos capaces de acusar, con más libertad y más notoria injusticia, al Sr. Calvelo; esta Inspección, es de parecer que, si bien es cierto que hay que reconocer en el Sr. Calvelo falta el tacto para no perder la cordial amistad e íntima relación que el Maestro debe tener con sus convecinos y el ascendiente moral sobre ellos, también es innegable que en el expediente no se prueban de una manera conclusa las acusaciones de que ha sido objeto.

En su vista, esta Inspección se atrevería a proponer a V. S. I. el traslado del Sr. Calvelo a otra escuela de igual clase y categoría, por creer que así terminarían los rencores y sería beneficioso para la enseñanza; mas como este traslado necesariamente tenía que revestir el carácter de medida disciplinaria, y el Sr. Calvelo, a juicio del que suscribe, no se ha hecho acreedor a ella, opina, en consecuencia, que procede sobreseer el expediente por no resultar probadas las acusaciones que lo motivaron.

No obstante, V. S. I. resolverá lo que mejor crea en justicia.

Dios gue a V. S. I. ms. as.

Pontevedra 28 Abril 1896

El Inspector

Salvr. de J. Ponsoda 


\section{Documento 5. Informe dos relatores nomeados pola Xunta provincial de Instrución pública de Pontevedra}

Los firmantes, encargados de emitir informe en el expediente instruido a D. Hermenegildo Calvelo, han examinado con todo detenimiento dicho expediente y de su estudio deducen:

$1^{\circ}$ Que en la villa de Cuntis se halla dividida la opinión formada a propósito de la conducta moral y profesional del indicado Maestro.

$2^{\circ}$ Que en las manifestaciones hechas por los testigos que no censuran al D. Hermenegildo, se contienen casi exclusivamente negaciones a los cargos de los que le censuran; pero no se hace constar, ni se prueba, como debiera esperarse, lo contrario; especialmente en lo que se refiere a la conducta profesional del Maestro, que tan fácilmente podría vindicarse, ya por medio de informaciones a este propósito que se refirieran a actos concretos y ya con certificaciones de actas de exámenes que hubiera presidido la Junta local.

$3^{\circ}$ Que en contraposición a lo que se dice en el número que precede, los testigos de cargo hacen afirmaciones absolutas y concretas que no pueden ser desvirtuadas totalmente por las declaraciones de no constar hechas por los de descargo.

$4^{\circ}$ Que de todo ello resulta que se discute la conducta del Maestro, tanto en su vida privada, como en su vida profesional, y que se discute por una gran parte del pueblo en donde ejerce su cargo.

$5^{\circ}$ Que aunque no tengan en absoluto razón los que le inculpan, nadie, después de leído el expediente, podrá asegurar la inocencia de D. Hermenegildo, pues ya que no otra cosa, se adquiere la duda de si su comportamiento se ajusta a lo que su condición exije [sic], y esta duda acusa, por lo menos, falta de tacto, de ductilidad de carácter, y de otras cualidades que deben adornar a todo buen maestro.

$6^{\circ}$ Que por todo lo expuesto se hace preciso que el D. Hermenegildo Calvelo deje de ser maestro de la villa de Cuntis, siendo trasladado forzosamente a otra escuela de su misma categoría, en la que pueda demostrar que no es a él achacable la enemiga que le tienen gran parte de los vecinos del pueblo en que hoy ejerce.

Con lo expuesto consideran los que suscriben evacuado el informe que la Junta les encomendó.

Pontevedra 20 de Junio de 1896

Victoriano Encinas Emilio Álvarez Giménez Joaquín López Paratcha 


\section{Documento 6. Informe do relator do Consello universitario de Santiago}

El ponente que suscribe ha examinado con detenimiento el expediente instruido a D. Hermenegildo Calvelo, maestro de Cuntis, por supuestas faltas observadas en su conducta profesional y moral.

Se ha supuesto que este Maestro no cumplía con sus deberes profesionales, que faltaba a su esposa y a su madre y que se embriagaba; y resulta probado todo lo contrario.

De los cargos que se hacen al Maestro Sr. Calvelo, de sus descargos, y de las declaraciones prestadas por la prueba testifical, resulta:

Que el Sr. Calvelo combate los cargos con abundancia de datos y detalles; prueba que su esposa es la culpable de que ambos no hagan vida común; ni puede embriagarse en la taberna que sus denunciadores citan, puesto que no existe, ni cabe suponer que se embriague quien cultive la amistad y frecuente el trato de personas tan distinguidas como las que en el expediente se citan.

Sólo el juez municipal, con unos cinco testigos, deponen en contra del Sr. Calvelo; pero estas declaraciones quedan anuladas por las que han prestado gran número de testigos, que afirman cumple a satisfacción con sus deberes profesionales, están satisfechos de la enseñanza, y nada absolutamente tienen que observar respecto a su conducta moral y privada. Y estas declaraciones tienen tanta más fuerza, cuanto en ellas figuran las prestadas por el Sr. Cura párroco y otras personas de reconocida ilustración y arraigo en la localidad.

Dos Inspectores provinciales, el de Pontevedra y el de la Coruña, con motivo de este expediente, han girado visita extraordinaria a la Escuela de Cuntis y en sus respectivos informes testifican que el Sr. Calvelo es un Maestro competente y celoso, advierten adelantos en la enseñanza, y consideran intachable su conducta, contra la cual nada han podido observar.

La Junta local, primera autoridad que vela directamente por los intereses de la enseñanza, informa favorablemente al Maestro: nada ve censurable y estima como buena la conducta del Sr. Calvelo.

La Inspección no encuentra justificado cargo alguno y propone que se sobresea este expediente.

Una comisión de la Junta provincial, sin encontrar justificados los cargos, cree que el Maestro llegó a hacerse incompatible con algunos vecinos, y en esto fundada pide su traslado forzoso, con lo cual se conforma la Junta.

Es verosímil que esa incompatibilidad exista entre el Maestro y los que le denunciaron; como es posible que, si se examina este expediente, puede descubrirse que el Sr. Calvelo milite en política y en bando contrario al del que haya sido origen de estas diligencias; pero estas suposiciones no son, ni pueden ser, motivo 
legal para pedir la traslación forzosa de un Maestro que cumple con sus deberes, imponiéndole una corrección disciplinaria que le perjudica sobre manera.

El Ponente que suscribe opina y propone que debe sobreseerse este expediente sin nota desfavorable para el interesado.

V. I. y el Consejo resolverán, sin embargo, lo que estimen más acertado.

Santiago $1^{\mathrm{o}}$ de Noviembre de 1896

Gorgonio Hueso 